\title{
Loading characteristics of filter pretreated with anionic surfactant for monodisperse solid particles
}

\author{
Shinhao Yang ${ }^{\text {a }}$, Grace W.M. Lee ${ }^{\text {a,* }}$, Chin-Hsiang Luo ${ }^{b}$, Chih-Cheng Wu ${ }^{\text {a }}$, Kuo-Pin Yu ${ }^{\text {a }}$ \\ ${ }^{a}$ Graduate Institute of Environmental Engineering, National Taiwan University, 71 Chou-Shan Rd., Taipei 106, Taiwan, ROC \\ ${ }^{\mathrm{b}}$ Department of Environmental Engineering, Hung-Kuang University, 34, Chung-Chie Rd., Sha-Lu, Taichung, Taiwan, ROC
}

Received 6 September 2004; received in revised form 25 March 2005; accepted 30 June 2005

\begin{abstract}
Anionic surfactant (sodium oleate, SO) was used to pretreat polypropylene fibrous filters to make them negatively charged. This work examines the effects on particle loading of an anionic surfactant-pretreated filter. Also, the effects of various factors, such as the particle size, the face velocity, concentration of the surfactant, and particle distribution (mono and poly) on the particle loading characteristics were evaluated.

Experimental data reveal that the electric field of a filter treated with anionic surfactant (SO) could be directly measured using an electrofieldmeter, suggesting that the pretreatment with surfactant charged the filters. The results demonstrate that pretreating the filter with SO surfactant increases its particle-loading capacity. The clogging points of the untreated filter, and of the $0.01,0.05$ and $0.08 \mathrm{M}$ SOpretreated filter are 18,23, 28 and $33 \mathrm{~g} / \mathrm{m}^{2}$. The loading behavior of the SO-pretreated filter depended on the size of the particles and the operating face velocity. Additionally, the loading behavior of the SO-pretreated filter with polydisperse particles is much the same as that with monodisperse particles. However, the clogging point of the SO-pretreated filter with polydisperse particles is higher than that with monodisperse equal size.
\end{abstract}

(C) 2005 Elsevier B.V. All rights reserved.

Keywords: Particle; Loading characteristics; Anionic surfactant pretreated filter; Loading capacity; Clogging point

\section{Introduction}

On average, people spend as much as $87.2 \%$ of their time indoors [1], where various air pollutants are present. Suspended particulates indoors are important because they cause various respiratory diseases. Therefore more aircleaning devices are being utilized to remove them. Air filtration is an effective method for removing particles from a gas stream. Over recent years, electret filters have been extensively used to filter air, since they have a high filtration efficiency without an increased pressure drop. The particle capturing forces of the electret filters combine electrostatic mechanisms (Coulombic and dielectrophoretic) and conventional mechanisms, including impaction, interception, diffusion and gravitational settling. The efficiency of collection

\footnotetext{
* Corresponding author. Tel.: +886 2 23633249; fax: +886223633249.

E-mail addresses: d89541003@ntu.edu.tw (S. Yang), gracelee@ntu.edu.tw (G.W.M. Lee).
}

of an electret filter typically exceeds that of a conventional mechanical filter, especially for submicron particles. The performance characteristics of electret filters have been comprehensively examined [2-6].

Various studies have considered the variation in the particle loading characteristics of electret filters with particle loading [7-10]. The particle penetration through a conventional mechanical filter decreases as the particle loading increases. However, the loading characteristics of electret filters differ considerably from those of conventional mechanic filters. Penetration through an electret filter rises from an initially low value when the particles are loaded, rising to a maximum, and then falling to zero when a filter cake is formed. Two possible explanations have been provided for the increased penetration of the electret filter as particle loading begins. Baumgartner and Löffler [8] posited that the neutralization of charges on the filter fiber by deposited particles was responsible for the drop in efficiency. Brown et al. [9], however, concluded that charge 
neutralization was not responsible for the reduction of the collection efficiency by deposited particles, but rather, that the deposited particles screened the fiber charge.

Numerous parameters influence the loading behavior of the electret filter. Brown et al. [9] asserted that the drop in the collection efficiency of the electret filter was associated with the specific of loading particles. Walsh and Stenhouse [10] discovered that small particles accelerate filter clogging, quickly reducing the efficiency of filtration. Walsh and Stenhouse [11] investigated the effect of the face velocity on the loading performance of the electret filter. Barrett and Rousseau [12] examined the difference between the loading behaviors exhibited using solid and liquid.

Normally, electret filters are charged using three main processes, including corona charging, triboelectric charging and charging by induction [13]. Some researchers have noted that a fibrous filter coupled to an external electrical field also provides a high collection efficiency and a low-pressure drop, as does an electret filter [14,15]. In this work, anionic surfactant was used to charge the filter. Such a process is commonly applied to charge the uncharged filter in a water filtration system, to remove charged particles or ions. Pontié et al. [16] revealed that adding ionic or neutral surfactants increased the surface charges on a membrane. Kang and Shah [17] determined that a polypropylene membrane pretreated with dimethyl dioctadecy lammonium bromide has a positively charged surface, and so effectively removes negatively charged particles in wastewater. This pretreatment with surfactant has seldom been used in air filtration. Our pervious work has investigated the penetration through the filters pretreated with ionic surfactant [18]. Therefore, this work seeks to elucidate the loading characteristics of this new type electrically charged filter. However, no direct method was used to prove that the filter becomes charged by the surfactant pretreatment [18]. Additionally, the surface charge of the electret is estimated from the penetration data $[11,19,20]$. This is an indirect method of determining the surface charge. Hence, an electrofieldmeter was used to measure directly the electrical field of filter pretreated with anionic surfactant to demonstrate that the filter does become charged. Many of the cited investigations use monodisperse or polydisperse particles for experiments, but few investigations have compared the loading behaviors between both particle types. This work compares the loading behaviors obtained using monodisperse and polydisperse particles. The effects of the face velocity, particle size and the concentration of the surfactant on the particle loading of the anionic surfactant-pretreated filter were also investigated.

\section{Experimental methods}

\subsection{Tested filters}

A polypropylene fibrous filter was used in this study. Table 1 lists the characteristics of the polypropylene fibrous
Table 1

Characteristics of original untreated filters

\begin{tabular}{llllll}
\hline Fiber material & $\begin{array}{l}\text { Weight } \\
\text { of filter } \\
\left(\mathrm{g} / \mathrm{m}^{2}\right)\end{array}$ & $\begin{array}{l}\text { Filter } \\
\text { thickness } \\
(\mathrm{mm})\end{array}$ & $\begin{array}{l}\text { Fiber } \\
\text { diameter }^{\mathrm{a}} \\
(\mu \mathrm{m})\end{array}$ & $\begin{array}{l}\text { Calculated } \\
\text { packing } \\
\text { fraction }^{\mathrm{b}}\end{array}$ & $\begin{array}{l}\text { Pressure } \\
\text { drop }(\mathrm{Pa}) \\
\text { @ } U(\mathrm{~m} / \mathrm{s})\end{array}$ \\
\hline Polypropylene & 178.44 & 5.0 & 30.1 & 0.040 & $5.0 @ 0.1$ \\
\hline${ }^{\mathrm{a}}$ Diameter was measured by SEM experiments. \\
${ }^{\mathrm{b}}$ Calculated by the empirical model of Davies ${ }^{[21]}$.
\end{tabular}

filter. The filter was weighed using an electronic microbalance; the fiber diameter of the filter was measured using scanning electron micrograph (SEM); the thickness of the filter was measured using a ruler; the packing fraction calculated using the empirical model developed by Davies [21],

$\Delta p=\frac{v m U f(\alpha)}{r^{2}}$

$f(\alpha)=64 \alpha^{1.5}\left(1+56 \alpha^{3}\right)$

where $\Delta p$ is the pressure drop across the filter; $v$ is the air viscosity; $m$ is the thickness of the filter; $U$ is the face velocity; $r$ is the fiber radius, and a is the packing fraction. Solutions of the anionic surfactant, sodium oleate (SO, $\left.\mathrm{C}_{17} \mathrm{H}_{33} \mathrm{COONa}\right)$, with three concentrations $(0.01,0.05,0.08$ $\mathrm{M})$ were used to treat the polypropylene fibrous filters. Surfactant solutions were prepared by dissolving the surfactants in pure water. The filters were then soaked in the surfactant solution for $15 \mathrm{~min}$, and so became coated with the surfactants; the surfactants had one or many hydrocarbon chains that could hydrophobically bond to the surface of polypropylene [17]. After they had been soaked, the filters were dried in an oven at $105{ }^{\circ} \mathrm{C}$ for $12 \mathrm{~h}$.

\subsection{Electric field of the anionic surfactant pretreated filters}

This work studies the surface charge of the filters pretreated with an anionic surfactant. An electrofieldmeter (EFM 022, Wolfgang Warmbier Instruments Inc.) was used to measure the electric field $(E)$ of these filters. The distance between the sensor and the surface of the filter was maintained at $1 \mathrm{~cm}$. For each pretreating-surfactant concentration, ten pieces of the pretreated filters were used in measuring the electrical field.

\subsection{Experimental setup and procedures}

Fig. 1 schematically depicts the experimental setup. It comprises an particle generator, a neutralizer, a testing chamber that contains a filter holder and the tested filter, an particle electrometer, a condensation particle counter used to sample the particle concentrations upstream and downstream of the filter, and a pressure gauge to measure the pressure drop across the filter and a flow meter.

Monodisperse polystyrene latex (PSL, Duke Inc) particles were atomized using a Collison atomizer (model 


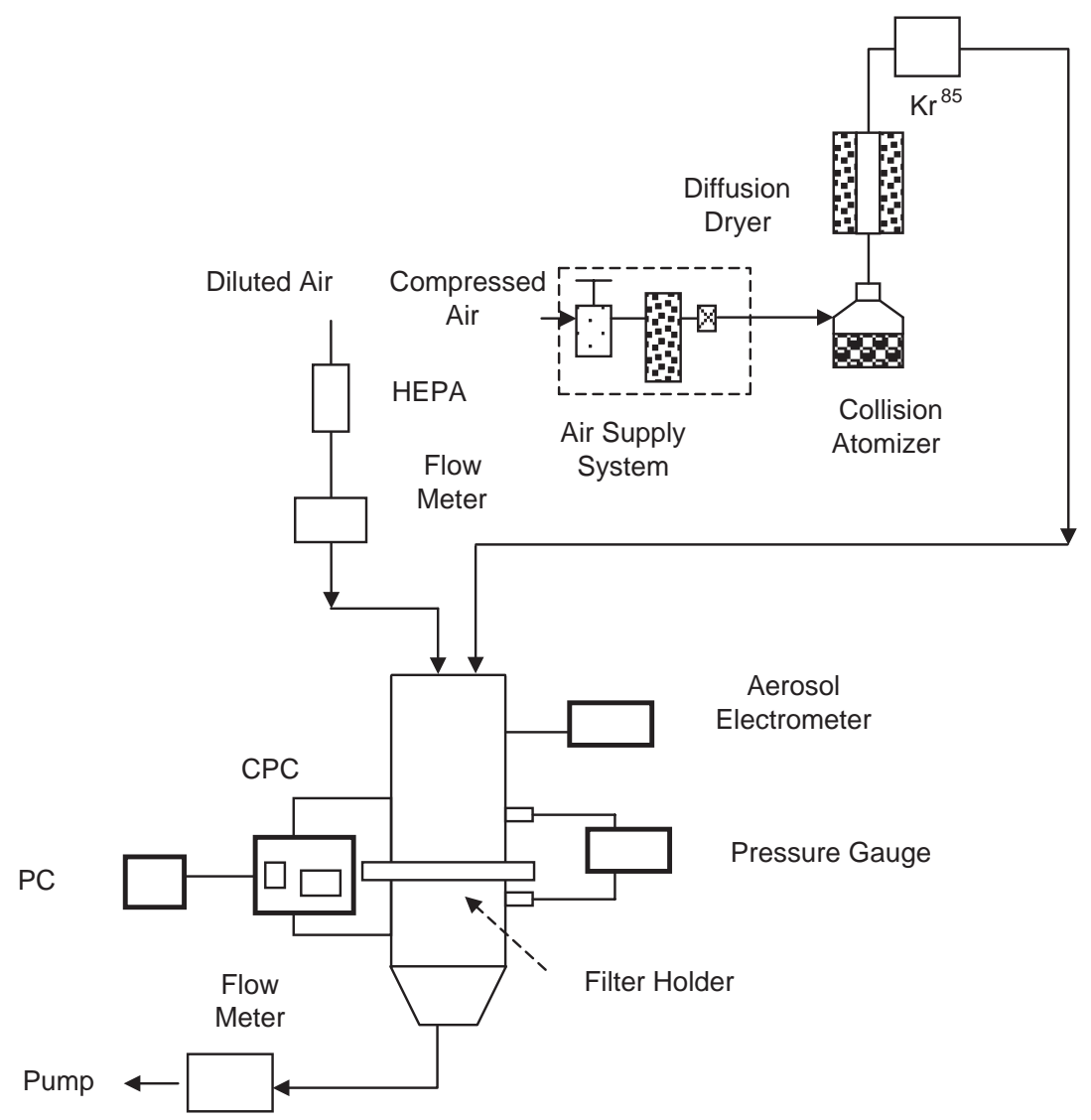

Fig. 1. Schematic diagram of the experimental system.

3076, TSI Inc) for testing. PSL particle sizes ranged from 0.03 to $0.93 \mu \mathrm{m}$ were used in evaluating the particle penetration through the filters. Of those PSL particles, only five PSL particle sizes $(0.20,0.30,0.46,0.80$ and 0.93 $\mu \mathrm{m})$ were used in the loading test because some particles were too small to be used in loading experiments. The monodispersity of the generated particles was confirmed using a Scanning Mobility Particle Sizer (SMPS, model 3936, TSI Inc) and an Aerodynamic Particle Sizer (APS, model 3310A, TSI Inc). The geometric standard deviation (GSD) of these generated particles, based on particle counts varied from 1.1 to 1.2. For further investigating the difference of loading behavior between using monodisperse and polydisperse particles, the polydisperse polystyrene latex particles were also applied for examining. We mixed the different percentage of monodisperse polystyrene latex to produce the polydisperse PSL particles. The size (CMD) of this polydisperse particle is $0.3 \mu \mathrm{m}$ and the GSD of this $0.3-\mu \mathrm{m}$ particle is 1.8 . The particle concentrations of monodisperse particles are about $5 \times 10^{4}$ (particles $/ \mathrm{cm}^{3}$ ) and the polydisperse particle concentration is approximately $6 \times 10^{4}$ (particles $\left./ \mathrm{cm}^{3}\right)$. Then, the tested particle was passed through a $\mathrm{Kr}-85$ radioactive source (model 3077, TSI Inc), which neutralized the particle to the Boltzmann charge equilibrium. After it had passed through the neutralizer, the tested particle was drawn through the testing chamber, in which it was mixed with the diluted clean air. An aerosol electrometer (model 3068, TSI Inc, MN) was applied to monitor the neutralization of the charge of the particle in the testing chamber. The penetration through the pretreated and untreated filters was measured using a condensation particle counter (CPC, model 3025A, TSI Inc.), which measured the particle concentrations upstream and downstream of the tested filter. The pressure drop across the tested filter was measured using a pressure gauge (Model 2000, Dwyer Instruments Inc) during the period of testing. The face velocity through the tested filter was controlled using a flow meter and a pump. The testing face velocities were varied from 0.05 to $0.2 \mathrm{~m} / \mathrm{s}$. At the end of the experiment, the filter was weighed to determine the mass collected per unit area. Under each filtration conditions, experiments were carried out repeatedly but with different periods of exposure, to yield filters in various particle-loading states.

Penetrations of 0.038 to $0.91 \mu \mathrm{m}$ by PSL monodisperse particle without any filter were measured to ensure that particle removal occurs only on the filter surface and not on the holder or any part of the test chamber. Particle concentrations immediately upstream and downstream of the filter holder were measured using a CPC. Penetration tests were undertaken at face velocities of $0.05,0.1$ and 0.2 $\mathrm{m} / \mathrm{s}$. The results from of evaluation, which are displayed in Fig. 2, clearly reveal that losses of submicron particles through the holder are very small $(<5 \%)$, verifying that particle removal could only occur across the tested filter. 


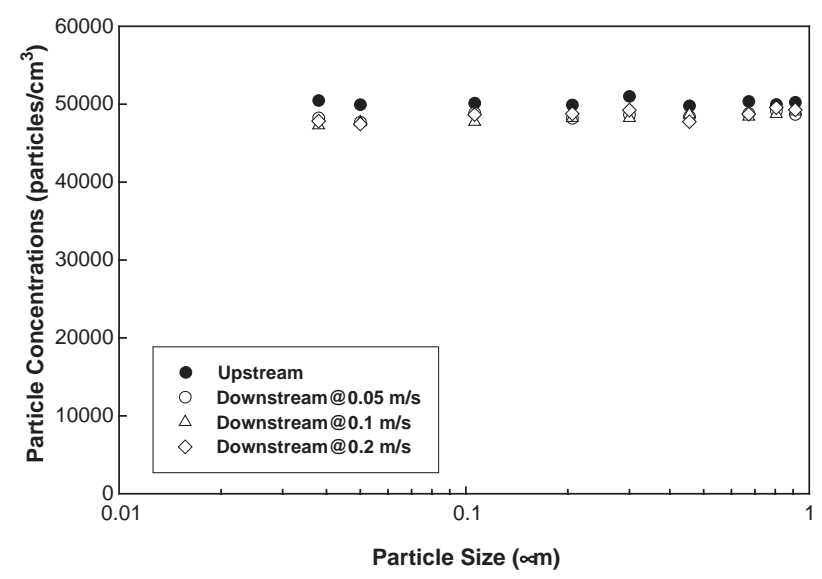

Fig. 2. Evaluation of particle losses through the test chamber and filter holder.

\subsection{Particle penetration calculation}

The particle penetration through a filter is given by

$P=\frac{C_{\text {down }}}{C_{\text {up }}}$,

where $C_{\text {down }}$ and $C_{\text {up }}$ are the number concentrations measured downstream and upstream of the filter, respectively.

\subsection{Comparison of filter performance}

A good filter provides the highest collection efficiency with the lowest pressure drop. A useful index of quality for various filters is the quality factor, $q_{\mathrm{F}}$, defined as [22]

$q_{\mathrm{F}}=\frac{\ln (l / P)}{\Delta p}$,

where $P$ represents the particle penetration, and $\Delta p$ is the pressure drop across the filter. A better filter has a larger $q_{\mathrm{F}}$. Values of $q_{\mathrm{F}}$ can be compared only when the face velocity and size of the test particle are held constant.

\section{Results and discussion}

\subsection{Properties of SO-pretreated filters}

Fig. 3 plots the pressure drop across the untreated filter and the SO-pretreated filters versus the sampling face velocity. The pressure drop increases with the face velocity, suggesting that the airflow through the tested filters is laminar. As plotted in Fig. 3, the pressure drops across the filters pretreated with $0.01,0.05$ and $0.08 \mathrm{M} \mathrm{SO}$ negligibly exceed that across the untreated filter. The pressure drop across the filter has been associated with its fiber diameter, its packing fraction and its filter thickness [21]. The data reveal the pressure drops across those filters are almost the same, indicating that the pretreatment with surfactant probably does not affect the structure of the filters. Furthermore, the fiber diameter, the packing fraction and the thickness of the SO-pretreated filter are almost the same as those of the untreated filter, as displayed in Tables 1 and 2. Both findings support the fact that the anionic surfactants coat the fiber, forming thin surfactant membranes. The data also demonstrate that the mechanical filtration forces of a filter pretreated with SO surfactant are almost the same as those of an untreated filter. Although the surfactant membrane does not markedly change the fiber's diameter, the packing fraction or the fiber thickness, it does increase the mass of the SO pretreated filters. Therefore the surfactant membrane on the filter fiber only increases the density of the filter fiber.

An electrofieldmeter was used to sample directly the electric field on the surfaces of SO-pretreated filters, to prove that the filter becomes charged during pretreatment with surfactant. The SO-pretreated filters that had just been removed from the oven and conditioned at room temperature were sampled. The data reveal that the electric field of the untreated filter was $-1.10 \times 10^{2} \mathrm{~V} / \mathrm{m}$, and those of the filters pretreated with $0.01,0.05$ and $0.08 \mathrm{M}$ SO were $-5.50 \times 10^{3},-9.72 \times 10^{3}$ and $-1.22 \times 10^{4} \mathrm{~V} / \mathrm{m}$, respectively. These data indicate that pretreatment with $\mathrm{SO}$ anionic surfactant increases the charge on the surface of the filter. The filters were negatively charged when treated with anionic surfactant because polypropylene fiber may bond with the carbon-chain group ion of the surfactant. Anionic surfactant molecules ( $\mathrm{SO}$ ) dissociate in water to generate carbon-chain group ions $\left(\mathrm{C}_{17} \mathrm{H}_{33} \mathrm{COO}^{-}\right)$and complementary ions $\left(\mathrm{Na}^{+}\right)$. When an untreated filter is immersed in a surfactant solution, the carbon-chain group ion interacts with the polypropylene fiber. The bonding force between the polypropylene fiber and the carbon-chain group ion exceeds that of between the carbon-chain group ion and its original complementary ion. Therefore, when the filters were removed from the surfactant solution, some of the surfactant molecules that coated the filter were only negative carbon-chain group ions, which negatively charged

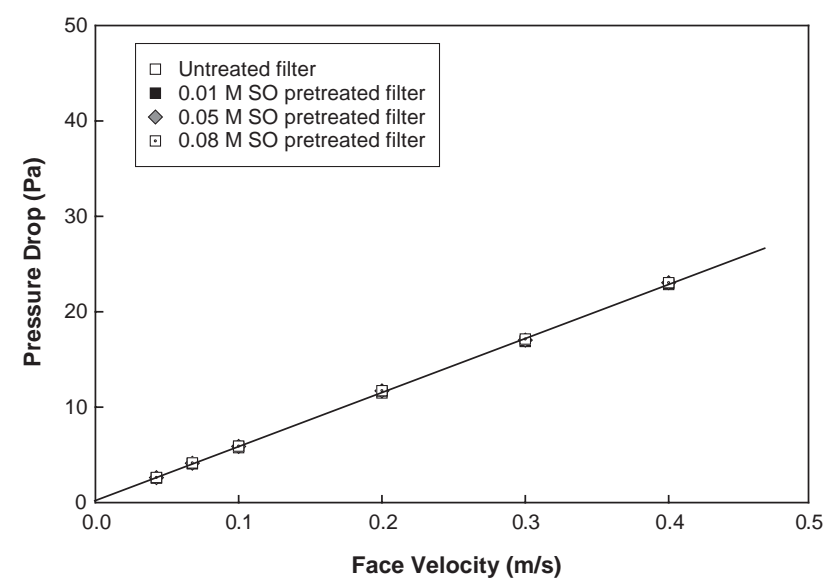

Fig. 3. Pressure drop of the tested filters versus face velocity. 
Table 2

Characteristics of SO pretreated filters

\begin{tabular}{lllll}
\hline Fiber material & $\begin{array}{l}\text { Weight of } \\
\text { filter }\left(\mathrm{g} / \mathrm{m}^{2}\right)\end{array}$ & $\begin{array}{l}\text { Filter thickness } \\
(\mathrm{mm})\end{array}$ & $\begin{array}{l}\text { Fiber diameter } \\
(\mu \mathrm{m})\end{array}$ & $\begin{array}{l}\text { Calculated packing } \\
\text { fraction }\end{array}$ \\
\hline Polypropylene/0.01 M SO & 186.15 & 5.0 & 30.1 & 0.040 \\
Polypropylene/0.05 M SO & 199.89 & 5.0 & 30.2 & 0.041 \\
Polypropylene/0.08 M SO & 208.44 & 5.0 & 30.3 & $5.0 @ 0.1$ \\
\hline
\end{tabular}

${ }^{\text {a }}$ Diameter was measured by SEM experiments.

b Calculated by the empirical model of Davies ${ }^{[21]}$.

the filter. The experimental findings also demonstrate that the electric field associated with the SO-pretreated filters increases with the concentration of the SO, probably because the number of carbon-chain-group ions that coat the filter increases with the concentration of the surfactant.

\subsection{Loading characteristics of the SO-pretreated filters}

Fig. 4 plots the experimental data the initial penetration of "Boltzmann equilibrium" PSL particles through the untreated filter and through filters pretreated with $\mathrm{SO}$ at three concentrations. The face velocity was maintained at $0.1 \mathrm{~m} / \mathrm{s}$ in all tests. The initial penetrations through these three SO-pretreated filters were less than that through the untreated filter. The initial penetrations of the $0.3 \mu \mathrm{m}$ particle through $0.01,0.05$ and $0.08 \mathrm{M} \mathrm{SO}$-pretreated filters, and through the untreated filter were $50 \%, 45 \%, 38 \%$ and $75 \%$, respectively. These data show that pretreatment with SO reduced the initial penetration through the filter, by strengthening electrostatic force.

Fig. 5a plots the particle penetration and pressure drop in a $0.05 \mathrm{M}$ SO-pretreated filter versus loading with a $0.3 \mu \mathrm{m}$ "Boltzmann equilibrium" PSL particle at a face velocity of $0.1 \mathrm{~m} / \mathrm{s}$. The data indicate that the initial penetration increases with the deposited particles, reducing the electrostatic capture force in the SO-pretreated filter. The deposited particles generate dendritic structures on the filter fibers, which contribute to the increase in the mechanical capture force. Hence, the penetration reaches a maximum when the

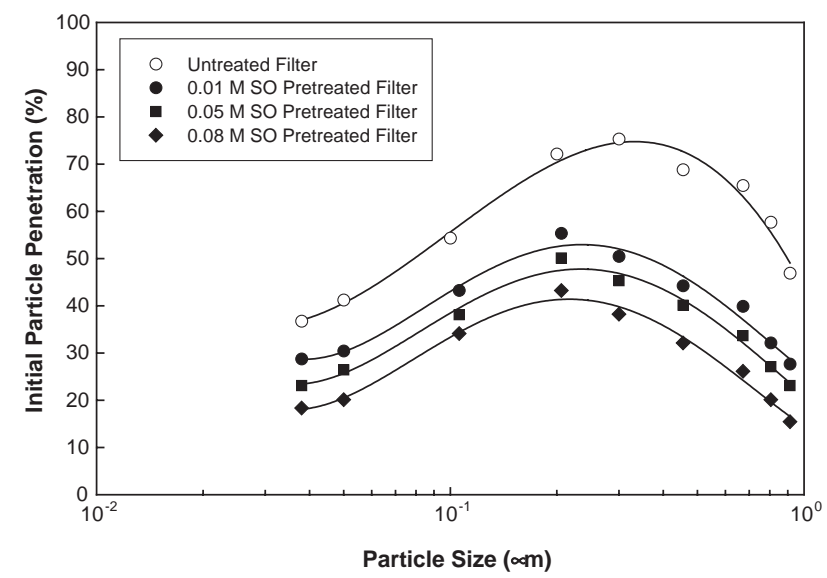

Fig. 4. Initial particle penetration through the SO pretreated and untreated filters at face velocity of $0.1 \mathrm{~m} / \mathrm{s}$. rise in the mechanical force caused by the growth of dendritic structures equals the reduction in the electrostatic force. Beyond the maximum, the penetration falls to zero as the filter cake is formed. Accordingly, the entire loading process can probably be regarded as involving two steps. The pressure drop data also reveal that the loading process includes two steps. During the first, the increase in the pressure drop is small, but during the second, the pressure drop increases linearly with particle deposited. The filter clogging (cake formation) point can also be determined from the pressure data. The clogging point under such conditions is approximately $28 \mathrm{~g} / \mathrm{m}^{2}$ (mass of the deposited particles/filter surface area). These results are similar to those of Walsh and Stenhouse [10].

Fig. $5 \mathrm{~b}$ plots the particle penetration and pressure drop of an untreated filter versus particle loading with $0.3 \mu \mathrm{m}$
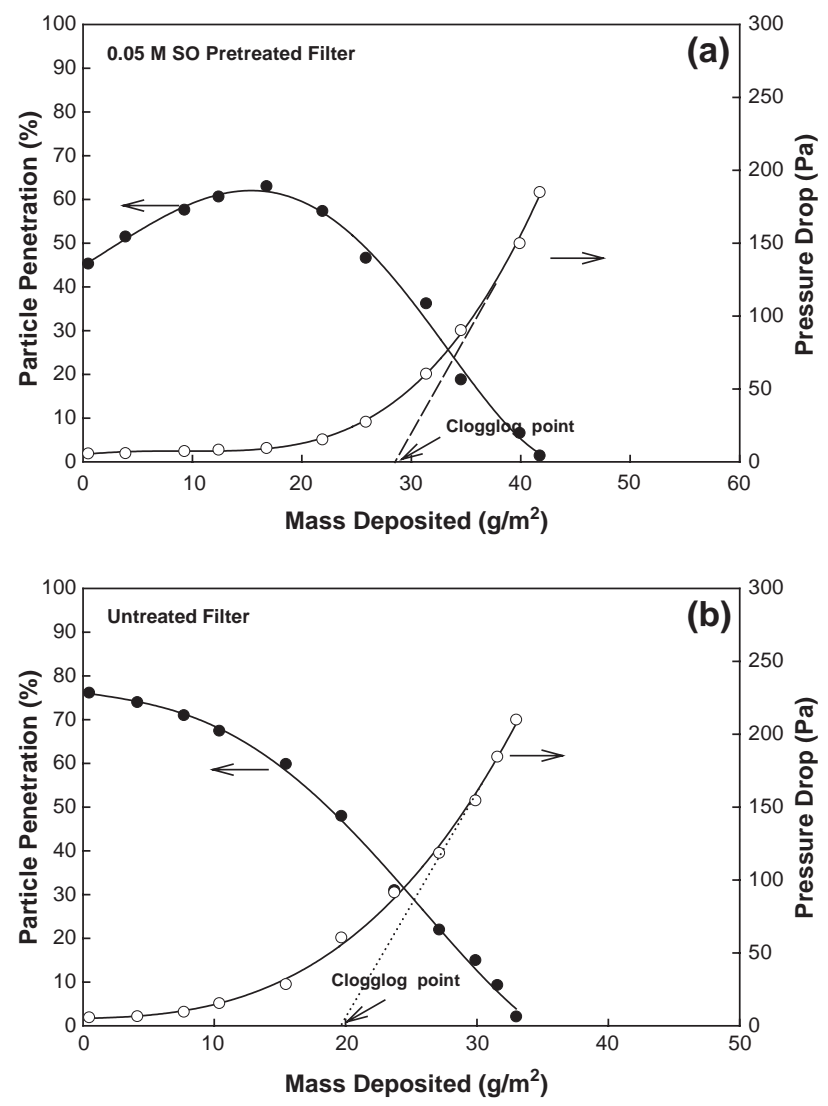

Fig. 5. Particle penetration and pressure drop versus particle loading with $0.3-\mu \mathrm{m}$ particles at face velocity of $0.1 \mathrm{~m} / \mathrm{s}$. (5a. $0.05 \mathrm{M}$ SO pretreated filter; $5 b$ untreated filter). 
"Boltzmann equilibrium" PSL particles at a face velocity of $0.1 \mathrm{~m} / \mathrm{s}$. The figure reveals that loading can also be regarded as two steps. In the first, the penetration falls slightly as particle deposited increases, which behavior differs from that of particle loading onto the SO-pretreated filter because the surface of the untreated filter is uncharged. Only the contribution of the dendritic structures to the mechanical force affects the loading behavior. The clogging point under such conditions is around $18 \mathrm{~g} / \mathrm{m}^{2}$. The clogging point of the $0.05 \mathrm{M}$ SO-pretreated filter is higher that of the untreated filter when tested with $0.3-\mu \mathrm{m}$ monodisperse PSL particles. Therefore, pretreatment with anionic surfactant improves the loading capacity of the filter, because pretreatment with anionic surfactant increases the electrostatic force on the filter.

Fig. 6 plots particle penetration against particle loading for $0.01,0.05$ and $0.08 \mathrm{M}$ SO-pretreated filters with $0.3 \mu \mathrm{m}$ "Boltzmann equilibrium" PSL particles at a face velocity of $0.1 \mathrm{~m} / \mathrm{s}$. The data demonstrate that penetration through the filter pretreated with more dilute SO reaches the maximum and zero values more rapidly than that through the other filters. The experimental data also show that the surface of the $0.08 \mathrm{M}$ SO-pretreated filter has the strongest electric field, followed by that of the $0.05 \mathrm{M}$ SO-pretreated filter, and then that the $0.01 \mathrm{M}$ SO-pretreated filter, which has the lowest surface electric field. Accordingly, the deposited particles reduce the electrostatic capture force of the filter with a lower surface charge more rapidly, indicating that the electrostatic efficiency of a filter with a lower surface charge is degraded more quickly.

Fig. 7 plots the pressure drop across $0.01,0.05$ and 0.08 M SO-pretreated filters against particle loading with $0.3 \mu \mathrm{m}$ "Boltzmann equilibrium" PSL particles at a face velocity of $0.1 \mathrm{~m} / \mathrm{s}$. Fig. 7 reveals that the filter pretreated with more dilute SO reaches its clogging point sooner, revealing that the charge on the filter governs the relationship between the pressure drop and the deposited mass. The clogging points of the $0.01,0.05$ and $0.08 \mathrm{M} \mathrm{SO}$ pretreated filter are 23, 28 and $33 \mathrm{~g} / \mathrm{m}^{2}$. These findings demonstrate that the loading

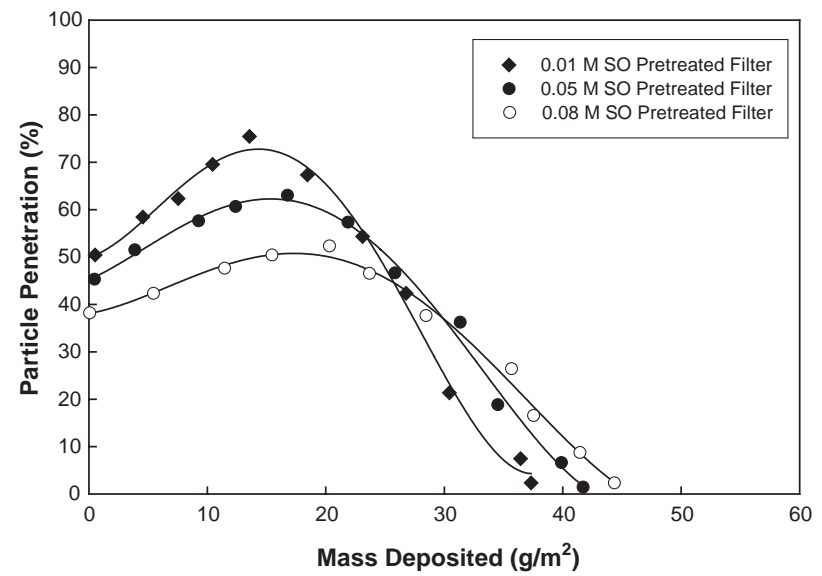

Fig. 6. Particle penetration versus particle loading for $0.01,0.05$ and $0.08 \mathrm{M}$ SO pretreated filters with $0.3-\mu \mathrm{m}$ particles at face velocity of $0.1 \mathrm{~m} / \mathrm{s}$.

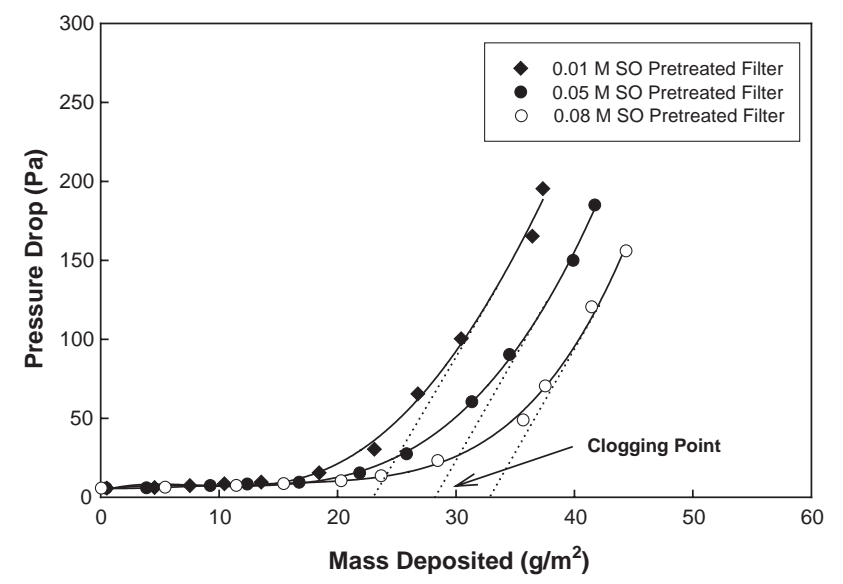

Fig. 7. Pressure drop versus particle loading for $0.01,0.05$ and $0.08 \mathrm{M}$ SO pretreated filters with $0.3-\mu \mathrm{m}$ particles at face velocity of $0.1 \mathrm{~m} / \mathrm{s}$.

capacity of the filter is higher when the surface charge on the filter is higher.

\subsection{Effect of particle size on particle loading}

Fig. 4 shows that the initial particle penetration through the SO-pretreated filter is a function of the particle size, and that this behavior is just like that of the electret filter. However, the effect of particle size on the loading behavior of the SO-pretreated filter remains unclear. Fig. 8 plots the particle penetration versus particle loading for $0.05 \mathrm{M} \mathrm{SO}-$ pretreated filters, for particles of various sizes $(0.20,0.30$, $0.46,0.80$ and $0.91 \mu \mathrm{m})$, at a face velocity of $0.1 \mathrm{~m} / \mathrm{s}$. The data indicate that the penetration of smaller particles increases more rapidly in the initial stage of particle loading, suggesting that the deposited mass of smaller particle reduces the electrostatic capture force of the $0.05 \mathrm{M}$ SOpretreated filter more quickly than does the deposited mass of large particle. The experimental data also demonstrate that the penetration of a smaller particle reaches a maximum and then falls to zero more rapidly. Fig. 9 plots the pressure drop versus particle loading for $0.05 \mathrm{M}$ SO-pretreated filters

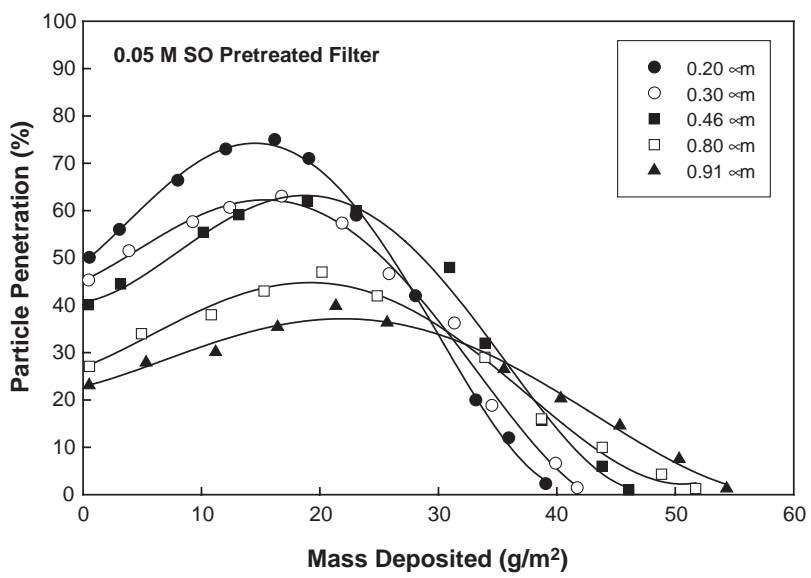

Fig. 8. Particle penetration versus particle loading for $0.05 \mathrm{M}$ SO pretreated filters with different particle size at face velocity of $0.1 \mathrm{~m} / \mathrm{s}$. 


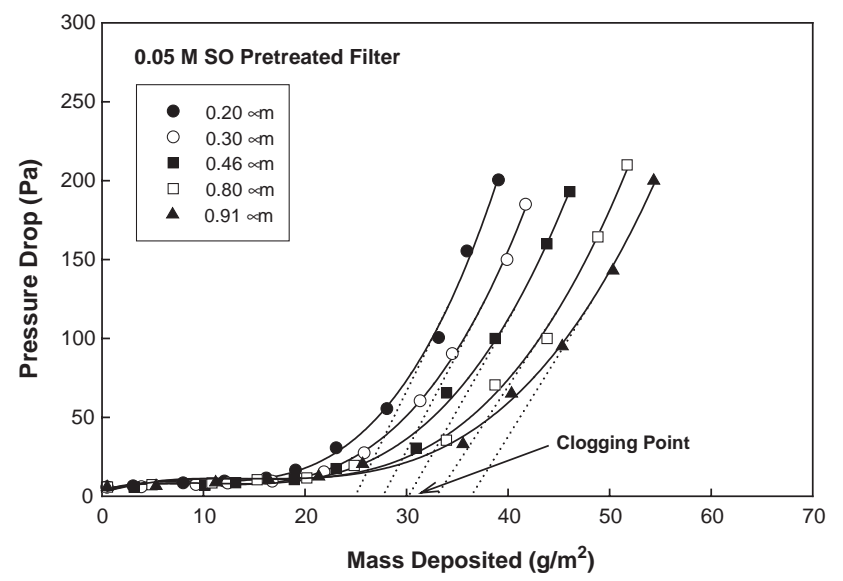

Fig. 9. Pressure drop versus particle loading for $0.05 \mathrm{M} \mathrm{SO}$ pretreated filters with different particle size at face velocity of $0.1 \mathrm{~m} / \mathrm{s}$.

with various particle sizes at a face velocity of $0.1 \mathrm{~m} / \mathrm{s}$. The data show that the $0.05 \mathrm{M}$ SO-pretreated filter clogs more quickly when loaded with smaller particles. Other investigations have also established that smaller particles clog electret filters more rapidly $[2,10]$. The findings herein agree strongly with previously published findings, mainly because the dendritic structures on the filter fibers grow more rapidly when the tested filters are loaded with smaller particles [10]. Therefore, when the tested filters were loaded with smaller particles, the improvement in the mechanical capture force exceeded that in the initial stage of loading and the penetration reached its maximum more rapidly; also, the clogging point was lower.

\subsection{Effect of face velocity on particle loading}

Fig. 10 plots particle penetration against particle loading for $0.05 \mathrm{M}$ SO-pretreated filters with $0.3 \mu \mathrm{m}$ "Boltzmann equilibrium" PSL particles at face velocities of $0.05,0.1$ and $0.2 \mathrm{~m} / \mathrm{s}$. The initial penetration through the $0.05 \mathrm{M} \mathrm{SO}-$ pretreated filter increases with the face velocity. This finding

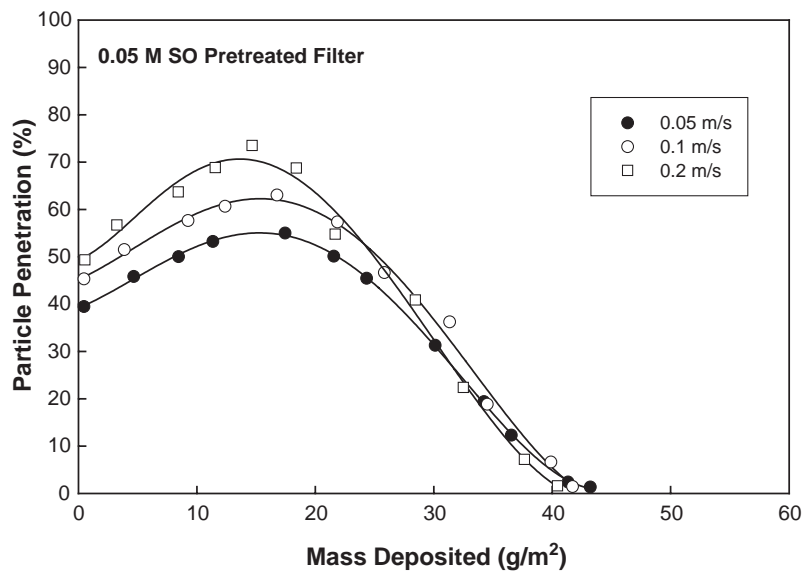

Fig. 10. Particle penetration versus particle loading for $0.05 \mathrm{M}$ SO pretreated filters with $0.3-\mu \mathrm{m}$ particles at face velocities of $0.05,0.1$ and $0.2 \mathrm{~m} / \mathrm{s}$.

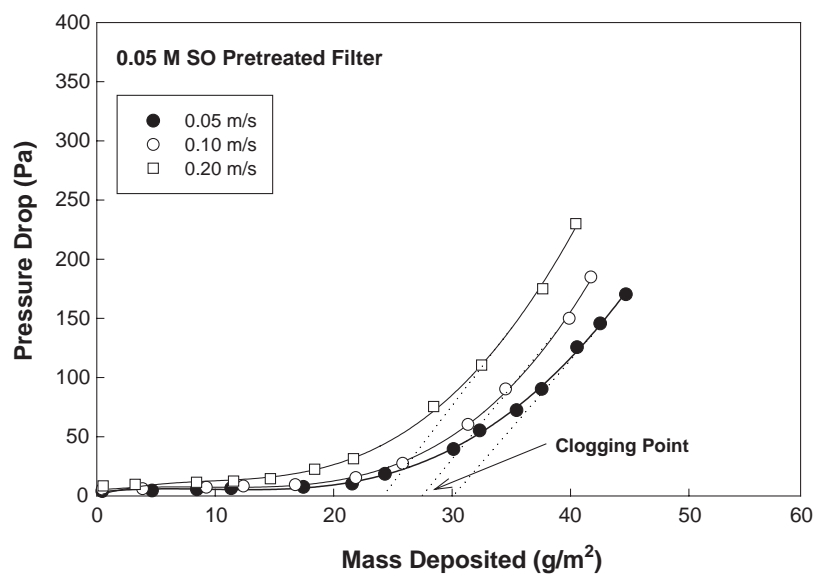

Fig. 11. Pressure drop versus particle loading for $0.05 \mathrm{M}$ SO pretreated filters with $0.3-\mu \mathrm{m}$ particles at face velocities of $0.05,0.1$ and $0.2 \mathrm{~m} / \mathrm{s}$.

follows the fact that the dominant mechanisms by which the submicron particles are filtered through the charged filter are electrostatic attraction and diffusion. A higher face velocity is associated with a shorter residence time for particle deposition by electrostatic attraction and diffusion. The results also reveal that the penetration increases more quickly in the initial stage of loading at higher face velocity. The maximum penetration is obtained more quickly when the face velocity is higher because the electrostatic capture force of the $0.05 \mathrm{M}$ SO-pretreated filter decreases as the face velocity increases. Accordingly, the deposited particles reduce the electrostatic efficiency more rapidly at a higher face velocity. Fig. 11 plots the pressure drop versus particle loading for $0.05 \mathrm{M}$ SO-pretreated filters with $0.3 \mu \mathrm{m}$ "Boltzmann equilibrium" PSL particles at three face velocities. These data reveal that the pretreated filter clogs more quickly and that the filter cake is formed at a lower deposited mass when the face velocity is higher. Also, increasing the face velocity in the experiment reduces the electrostatic collection force. Therefore, the loading capacity of the SO-pretreated filter is lower at a higher face velocity.

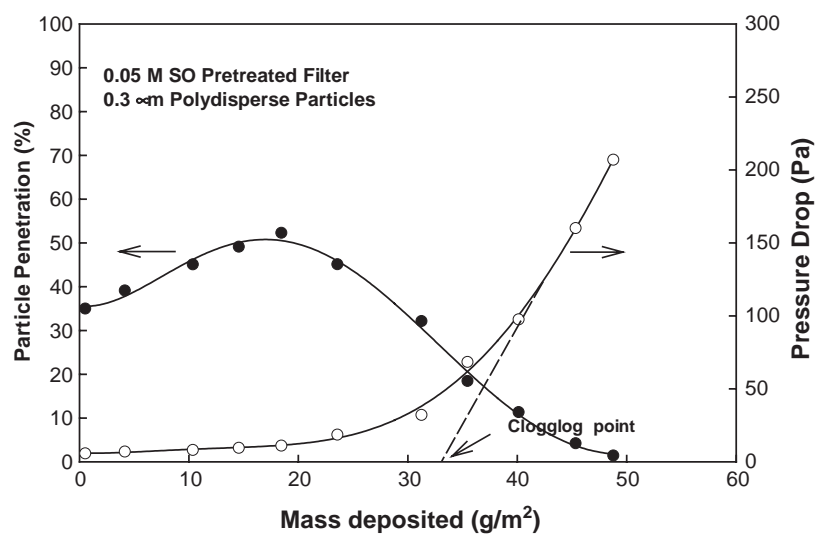

Fig. 12. Particle penetration and pressure drop versus particle loading for $0.05 \mathrm{M}$ SO pretreated filters with $0.3-\mu \mathrm{m}$ polydisperse particles at face velocity of $0.1 \mathrm{~m} / \mathrm{s}$. 


\subsection{Loading characteristics of SO-pretreated filter obtained using polydisperse particles}

Fig. 12 plots the particle penetration and pressure drop for a $0.05 \mathrm{M}$ SO-pretreated filter against loading with 0.3 $\mu \mathrm{m}$ "Boltzmann equilibrium" polydisperse PSL particles at a face velocity of $0.1 \mathrm{~m} / \mathrm{s}$. The experimental findings reveal that the particle-loading curve is very similar to the curve obtained with monodisperse particle loading. The initial penetration increases with the deposited particles to a maximum, before falling to zero as the filter cake is formed. Fig. 12 plots the pressure drop against the particle loading. The pressure drop data also demonstrate that the loading process comprises two steps. During the first, the increase in the pressure drop is small, whereas during the second, the pressure drop increases linearly with the particle loading.

The loading curve for $0.3-\mu \mathrm{m}$ polydisperse particles was compared with that for $0.3 \mu \mathrm{m}$ monodisperse particles. The initial penetration obtained using $0.3-\mu \mathrm{m}$ polydisperse particles is much lower than that obtained using $0.3-\mu \mathrm{m}$ monodisperse particles because the penetration of most of the $0.3-\mu \mathrm{m}$ polydisperse particles is lower than that of $0.3-$ $\mu \mathrm{m}$ monodisperse particles. The clogging point obtained using $0.3-\mu \mathrm{m}$ monodisperse particles is approximately $28 \mathrm{~g} /$ $\mathrm{m}^{2}$, and that obtained using $0.3 \mu \mathrm{m}$ polydisperse particles is around $33 \mathrm{~g} / \mathrm{m}^{2}$, suggesting that the clogging point for loading with polydisperse particles exceeds that with monodisperse particles of the same size, because most of the polydisperse particles are larger than $0.3 \mu \mathrm{m}$. Fig. 8 demonstrates that the clogging point increases with the particle size. Hence, during the loading process, the loading characteristic is major affected by the larger particles $(>0.3$ $\mu \mathrm{m})$ in the whole polydisperse particles.

\subsection{Quality factor of $S O$-pretreated filters}

A good filter exhibits not only a high collection efficiency but also a low pressure drop. The quality

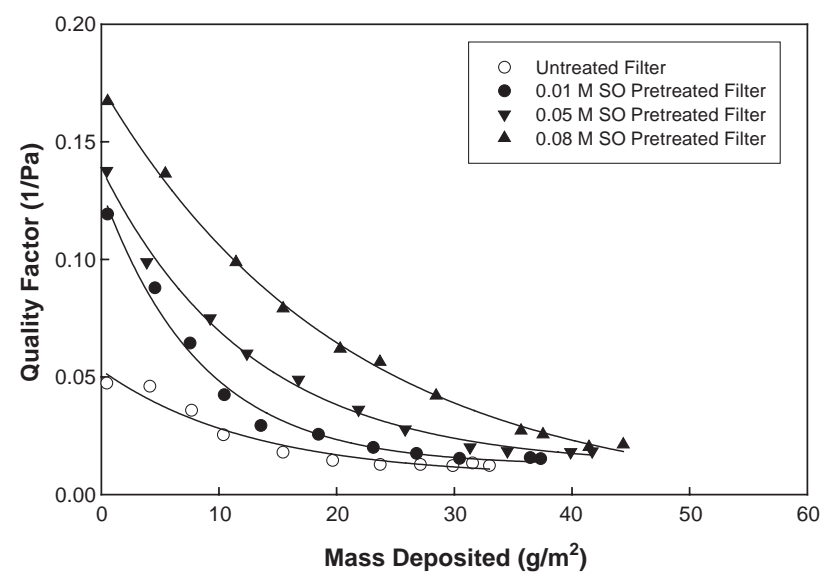

Fig. 13. Quality factor versus particle loading for untreated and SO pretreated filters with $0.3-\mu \mathrm{m}$ particles at face velocity of $0.1 \mathrm{~m} / \mathrm{s}$. factor, $q_{\mathrm{F}}$, is a good indicator of the performance of the filter. Fig. 13 plots the quality factor versus particle loading for untreated and SO-pretreated filters with 0.3 $\mu \mathrm{m}$ particles at a face velocity of $0.1 \mathrm{~m} / \mathrm{s}$. Fig. 3 reveals that the $q_{\mathrm{F}}$ of these tested filters decreases as the particle loading increases. The $q_{\mathrm{F}}$ of each SO-pretreated filter exceeds that of the untreated filter during particle loading. The filter pretreated with more concentrated SO has a higher $q_{\mathrm{F}}$ throughout particle loading. The data also indicate that the $q_{\mathrm{F}}$ of each SO-pretreated filter falls to its minimum at a higher loading mass than that of an untreated filter; also, the $q_{\mathrm{F}}$ of a filter pretreated with more concentrated SO reaches a minimum at higher particle loading because the filter pretreated with more concentrated SO has a stronger surface electric field, and a structure which is virtually unmodified by the pretreatment with the anionic surfactant. Therefore, a filter pretreated with more concentrated SO has a higher $q_{\mathrm{F}}$ and a much greater particle loading capacity.

\section{Conclusions}

The experimental findings reveal that the electric field of the untreated and $0.01,0.05$ and $0.08 \mathrm{M}$ SOpretreated filters are $1.10 \times 10^{2},-5.50 \times 10^{3},-9.72 \times$ $10^{3}$ and $-1.22 \times 10^{4} \mathrm{~V} / \mathrm{m}$, suggesting that pretreatment with SO anionic surfactant increases the surface charge of the filter, and the electric field of the SO pretreated filters increases with the concentration of the surfactant. That is direct evidence that this pretreatment can be used to charge the filter.

The clogging point of the $0.05 \mathrm{M}$ SO-pretreated filter was higher than that of the untreated filter when tested with monodisperse particles, revealing that pretreatment with anionic surfactant enhanced the loading capacity of the filter. The results also revel a that the filter pretreated with more concentrated had the higher particle loading capacity, because the filter treated with a higher concentration of SO has a larger surface charge, which is reduced more slowly by deposited particles.

The experimental data indicate that the clogging point of the SO-pretreated filters increases with the loading of larger particles. The SO-pretreated filter clogs more rapidly and the filter cake is formed at a lower deposited mass when the face velocity is higher. The loading curve of the SOpretreated filter with polydisperse particles is very similar to that of the filter with monodisperse particles. The clogging point of the SO-pretreated filter with polydisperse particles is higher than that of the filter pretreated with monodisperse of the same size. Furthermore, the $q_{\mathrm{F}}$ of the SO-pretreated filter exceeds that of the untreated filter. The filter pretreated with more concentrated SO has a higher $q_{\mathrm{F}}$ and a much higher particle loading capacity. This work may yield a new method of improving filtration efficiency and loading capacity. 


\section{Acknowledgements}

The authors would like to thank the National Science Council of Republic of China for financially supporting this research under Contract No. NSC. 91-EPA-Z-241-001.

\section{References}

[1] W. Lance, Indoor particles: a review, Journal of the Air \& Waste Management Association 46 (1996) 98-126.

[2] H.P. Baumgartner, F. Löffler, The collection performance of electret filters in the particle size range of $10 \mathrm{~nm}-10 \mu \mathrm{m}$, Journal of Aerosol Science 17 (1986) 438-445.

[3] R. Lathrache, H.J. Fissan, Enhancement of particle deposition in filters due to electrostatic effects, Filtration and Separation 24 (1987) $418-422$.

[4] R.A. Fjeld, T.M. Owens, The effect of particle charge on penetration in the electret filter, IEEE Transactions on Industry Applications 24 (1988) $725-731$.

[5] C.C. Chen, S.H. Huang, The effects of particle charge on the performance of a filtering facepiece, American Industrial Hygiene Association Journal 59 (1998) 227-233.

[6] AFFCO, Cleaner, healthier environments: AFFCO enhances air filter performance with electret composites, Filtration and Separation 35 (1998) 118-122.

[7] M. Lehtimäki, K. Heononen, Reliability of electret filters, Building and Environment 29 (1994) 353-355.

[8] H.P. Baumgartner, F. Löffler, Particle collection in electret fibers filters: a basic theoretical and experimental study, Filtration and Separation 23 (1987) 346-351.

[9] R.C. Brown, W.R. Gray, D.B. Blackford, G.J. Bostock, Effect of industrial aerosols on the performance of electrically charged filter material, Annals of Occupational Hygiene 32 (1988) 271-294.
[10] D.C. Walsh, J.I.T. Stenhouse, Clogging of an electrically active fibrous filter material: experimental results and two-dimensional simulations, Powder Technology 93 (1997) 63-75.

[11] D.C. Walsh, J.I.T. Stenhouse, Parameters affecting the loading behavior and degradation of electrically active filter materials, Aerosol Science and Technology 29 (1998) 419-432.

[12] L.W. Barrett, A.D. Rousseau, Aerosol loading performance of electret filter media, American Industrial Hygiene Association Journal 59 (1998) 532-539.

[13] R.C. Brown, Aerosol Filtration: an Integrated Approach to the Theory and Applications of Fibrous Filters, Pergamon Press, Oxford, 1993.

[14] J. Luckner, Z. Wertejuk, A. Podgorski, Effect of external electrostatic field on filtration efficiency of fibrous filters. Experimental studies and numerical simulations, Journal of Aerosol Science 25 (1994) S195-S196.

[15] J.K. Lee, S.C. Kim, J.H. Shin, J.E. Lee, J.H. Ku, H.S. Shin, Performance evaluation of electrostatically augmented air filters coupled with a corona precharger, Aerosol Science and Technology 35 (2001) 785-791.

[16] M. Pontié, X. Chasseray, D. Lemordant, J.M. Lainé, The streaming potential method for the characterization of ultrafiltration organic membranes and control of cleaning treatments, Journal of Membrane Science 129 (1997) 125-133.

[17] P.K. Kang, D.O. Shah, Filtration of nanoparticles with dimethyldioctadecyl-ammonium bromide treated microporous polypropylene filters, Langmuir 13 (1997) 1820-1826.

[18] S.H. Yang, W.M.G. Lee, Aerosol filtration by filters pretreated with ionic surfactants, Journal of Aerosol Science 34 (2003) S1023-S1024.

[19] F.J. Romay, B.Y.H. Liu, S.J. Chae, Experimental study of electrostatic capture mechanisms in commercial electret filters, Aerosol Science and Technology 28 (1998) 224-234.

[20] C.C. Chen, S.H. Huang, The effects of particle charge on the performance of a filtering facepiece, American Industrial Hygiene Association Journal 59 (1998) 227-233.

[21] C.N. Davies, Air Filtration, Academic Press, London, 1973.

[22] W.C. Hinds, Aerosol Technology, J. Wiley and Son, New York, 1982. 